\title{
Incidence and anatomical distribution of hand tumours: a Singapore study
}

\author{
Zhi Hao Tang$^{1}$, MBBS, MRCS, Vaikunthan Rajaratnam ${ }^{1}$, MBBS, FRCS, Vijayadwaja Desai ${ }^{1}$, MBBS, FRCPath
}

\begin{abstract}
INTRODUCTION Hand tumours are frequently encountered in clinical practice. A list of differential diagnoses of the most common hand tumours based on anatomical location would be helpful for clinicians. We aimed to determine the anatomical distribution of hand tumours seen at a hand surgery practice in Singapore.

METHODS The medical records of 50 men and 65 women (mean age 41.7 [range 17-74] years) who underwent excision of hand tumours between 1 June 2010 and 31 December 2012 were reviewed. The histological diagnoses and anatomical locations of the tumours were analysed. The locations were divided into three main groups: (a) distal to the metacarpophalangeal joints (MCPJs); (b) between the MCPJs and carpometacarpal joints (CMCJs); and (c) between the CMCJs and the radiocarpal joint (RCJ).

RESULTS Overall, the most common tumours excised from the hand were ganglions $(n=66 / 116,56.9 \%)$ and giant cell tumours of the tendon sheath (GCTTSs; $n=11 / 116,9.5 \%$ ). However, distal to the MCPJs, GCTTSs ( $n=11 / 39,28.2 \%$ ) were more common than ganglions ( $n=7 / 39,17.9 \%$ ). Most of the ganglions $(n=59 / 66,89.4 \%)$ arose from between the CMCJs and RCJ.

CONCLUSION Most hand tumours were benign. Ganglions were the most common tumours between the CMCJs and RCJ, while GCTTSs were the most common tumours distal to the MCPJs.
\end{abstract}

Keywords: anatomy, ganglion cysts, giant cell tumours, hand, neoplasms

\section{INTRODUCTION}

Hand tumours are encountered frequently, both in primary healthcare and specialist clinical practice. They have the potential to cause functional impairment. ${ }^{(1)}$ Studies suggest that $15 \%$ of all soft-tissue tumours are located in the hand region ${ }^{(2)}$ and $6 \%$ of bony cancers occur in the hand. ${ }^{(3)}$ Simon et al reported that a majority of primary hand bone tumours were found in the phalanges. ${ }^{(4)}$ In their study, skeletal tumours found in the hand were most often of cartilaginous origin, followed by bone cysts and osteogenic tumours. However, the study did not include soft-tissue tumours. In general, there is a lack of studies showing the anatomical distribution of all hand tumours. This study investigated the anatomical distribution of both soft-tissue and bony hand tumours excised between June 2010 and December 2012 at Khoo Teck Puat Hospital, a district general hospital in Singapore.

Hand tumours often present as clinically palpable lumps. Besides history-taking, clinical examination to arrive at differential diagnoses includes assessing for location, size, consistency, presence of skin changes, whether the lump appears attached to the skin or underlying structures, and whether the lump transilluminates. The anatomical location of clinically palpable hand tumours can easily be defined on clinical examination most of the time. Knowledge of the most common differential diagnoses based on the anatomical location of a hand tumour would allow physicians to narrow down the list of differential diagnoses, and treat and advise patients appropriately.

\section{METHODS}

This retrospective study reviewed all patients who had undergone excision of hand tumours between 1 June 2010 and 31 December 2012 at a hand surgery service in Singapore. The following patient data was collected from both hard copy notes and electronic records: age and gender; tumour location; laterality; duration of symptoms; time interval between development of symptoms and surgery; and histological diagnosis. The list of patients was obtained from the histological records of all hand tumours excised during the study period. The histological specimens were read by qualified pathologists at our centre.

The anatomical location of the tumours was divided into three different groups. Group I included tumours located distal to the metacarpophalangeal joints (MCPJs). Group II consisted of tumours proximal to the MCPJs and distal to the carpometacarpal joints (CMCJs). Group III were tumours proximal to the CMCJs and distal to the radiocarpal joint (RCJ). For tumours located over joints, if the bulk of the tumour was clinically proximal to the joint line, the tumour was classified as proximal to the joint and vice versa. Our study analysed the different histological diagnoses of hand tumours at each anatomical location.

\section{RESULTS}

A total of 116 hand tumours were excised from 115 patients within the period of study. Patient characteristics are shown in Table I. Overall, ganglion was the most common tumour excised, making up 66 (56.9\%) of 116 tumours. The second most common tumour was giant cell tumour of the tendon

${ }^{1}$ Department of Orthopaedic Surgery, Khoo Teck Puat Hospital, Singapore

Correspondence: Dr Tang Zhi Hao, Senior Resident, Department of Orthopaedic Surgery, Khoo Teck Puat Hospital, 90 Yishun Central, Singapore 768828. ZhiHao.Tang@mohh.com.sg 
Table I. Patient profile $(n=115)$.

\begin{tabular}{lc}
\hline Variable & No. (\%) \\
\hline Age $(\mathbf{y r})^{*}$ & $41.7(17-74)$ \\
Gender & $65(56.5)$ \\
Female & $50(43.5)$ \\
Male & \\
Ethnicity & $69(60.0)$ \\
Chinese & $29(25.2)$ \\
Malay & $12(10.4)$ \\
Indian & $5(4.3)$ \\
Others & \\
Laterality of tumour $(\mathbf{n}=\mathbf{1 1 6})$ & $58(50.0)$ \\
Right & $58(50.0)$ \\
Left & \\
\hline
\end{tabular}

*Data presented as mean (range).

sheath (GCTTS), comprising 11 (9.5\%) tumours. Both of these common tumours were benign in our study. In total, $115(99.1 \%)$ out of 116 tumours were reported to be benign. Only $2(1.7 \%)$ tumours arose from within the bone, while the rest were softtissue tumours.

Out of 116 tumours, 39 (33.6\%) belonged to Group I (i.e. distal to the MCPJs), $11(9.5 \%)$ to Group II (i.e. between the MCPJs and CMCJs), and 66 (56.9\%) to Group III (i.e. between the CMCJs and $\mathrm{RCJ}$ ). The most common among the 39 tumours in Group I were GCTTSs $(\mathrm{n}=11,28.2 \%)$ and ganglions $(\mathrm{n}=7$, $17.9 \%$ ). A complete list of the tumours excised by location is shown in Table II. Among 11 GCTTSs, four arose from extensor tendons and six were from flexor tendons; there was no documentation of where one GCTTS had arisen from. Seven GCTTSs occurred from the index finger, two from the middle finger and two from the little finger. Only one of the 11 patients had a painful GCTTS.

The characteristics of patients with GCTTSs and those with ganglions are shown in Table III. For GCTTSs, the mean duration of having the lump before presentation to our clinic was 53.6 (range 4-272) weeks. The mean time interval between development of the lump and surgical excision was 58.2 (range 7-276) weeks. There was no history of trauma in any of the 11 patients with GCTTSs. Lipomas ( $n=3,27.3 \%)$ were the most common tumours excised in Group II, followed by epidermal cysts $(\mathrm{n}=2,18.2 \%)$ (Table II). In Group III, ganglions accounted for 59 (89.4\%) out of 66 tumours, with 24 coming from the volar aspect and 35 arising from the dorsal aspect. Lipomas were a distant second in terms of most common tumour in this region, comprising two of 66 $(3.0 \%)$ tumours. Out of 66 patients with ganglions, 28 presented with pain and 12 with increasing ganglion size. Four patients had presented with recurrence of ganglions, all of which arose between the $\mathrm{CMCJ}$ s and $\mathrm{RCJ}$. Out of the 66 ganglions excised in our study, 3 (4.5\%) had recurrence, which occurred at 12 weeks, 20 weeks and 45 weeks postoperatively. None of our patients returned for recurrence of GCTTS.

Among 46 patients with ganglions, the lumps were present for a mean duration of 62.5 months (range 1-1,044 weeks) before presentation to our clinic, and for a mean duration of
Table II. Type of tumours excised by location $(n=116)$.

\begin{tabular}{|c|c|}
\hline Location of excision & No. (\%) \\
\hline \multicolumn{2}{|l|}{ Distal to MCPJs $(n=39)$} \\
\hline Giant cell tumour of the tendon sheath & $11(28.2)$ \\
\hline Ganglion & $7(17.9)$ \\
\hline Epidermal inclusion cyst & $3(7.7)$ \\
\hline Pyogenic granuloma & $3(7.7)$ \\
\hline Scar/inflammation & $3(7.7)$ \\
\hline Mucous cyst & $3(7.7)$ \\
\hline Neuroma & $2(5.1)$ \\
\hline Exostosis & $1(2.6)$ \\
\hline Dermatofibroma & $1(2.6)$ \\
\hline Angiomatous tumour & $1(2.6)$ \\
\hline Fibroepithelial polyp & $1(2.6)$ \\
\hline Foreign body & $1(2.6)$ \\
\hline Thrombosed blood vessel & $1(2.6)$ \\
\hline Keratin plugging follicle & $1(2.6)$ \\
\hline \multicolumn{2}{|l|}{ Between MCPJs and CMCJs $(n=11)$} \\
\hline Lipoma & $3(27.3)$ \\
\hline Epidermal cyst & $2(18.2)$ \\
\hline Neurofibroma & $1(9.1)$ \\
\hline Eccrine poroma & $1(9.1)$ \\
\hline Schwannoma & $1(9.1)$ \\
\hline Psoriasis & $1(9.1)$ \\
\hline Epitheloid & $1(9.1)$ \\
\hline Dupuytren's contracture & $1(9.1)$ \\
\hline \multicolumn{2}{|l|}{ Between CMCJs and RCJ $(n=66)$} \\
\hline Ganglion & $59(89.4)$ \\
\hline Lipoma & $2(3.0)$ \\
\hline Haemangioma & $2(3.0)$ \\
\hline Neuroma & $1(1.5)$ \\
\hline Epidermal cyst & $1(1.5)$ \\
\hline Dermatofibroma & $1(1.5)$ \\
\hline
\end{tabular}

CMCJ: carpometacarpal joint; MCPJ: metacarpophalangeal joint; RCJ: radiocarpal joint

Table III. Profile of patients with GCTTSs or ganglions.

\begin{tabular}{lcc}
\hline Variable & \multicolumn{2}{c}{ No. (\%)/mean (range) } \\
\cline { 2 - 3 } & GCTTS (n= 11) & Ganglion (n = 66) \\
\hline $\begin{array}{l}\text { Age (yr) } \\
\text { Gender }\end{array}$ & $35.9(22-55)$ & $38.9(17-65)$ \\
Female & $3(27.3)$ & $44(66.7)$ \\
Male & $8(72.7)$ & $22(33.3)$ \\
Laterality of tumour & & $31(47.0)$ \\
Right & $9(81.8)$ & $35(53.0)$ \\
Left & $2(18.2)$ & \\
\hline
\end{tabular}

GCTTS: giant cell tumour of the tendon sheath

69.4 (range 4-1,052) weeks before surgical excision. For the rest of the patients, this information was not documented in the case notes.

Only one of the 116 tumours was found to be malignant. It was an epithelioid haemangioendothelioma excised from the right little finger metacarpal diaphysis of a 56-year-old man. He had presented to our clinic with a sudden onset of a rapidly enlarging 
mass over his right little finger metacarpal region of two weeks' duration. The tumour was excised one week after presentation.

\section{DISCUSSION}

Several case reports or collective reviews have reported on particular types of tumours. ${ }^{(5-7)}$ However, there are no studies on the anatomical distribution and histology of tumours of the hand. Our study helps to bridge the gap in this body of knowledge, showing that there is a correlation between tumour types and their anatomical distribution in the hand, which potentially aids in diagnostic decision-making. Many patients seek medical consultation because of the cosmetic appearance of their hands or anxiety over the possibility of malignant growth. ${ }^{(8)}$

Our findings were consistent with those in the literature that benign tumours are more common than malignant tumours of the hand. ${ }^{(9,10)}$ Overall, we showed that ganglions were the most common tumours excised from the hand. However, the actual incidence may be higher, as ganglions can be asymptomatic and may not necessitate excision. In one study, Barnes et al reported that only $19.5 \%$ of patients had symptoms other than swelling. ${ }^{(11)}$ In another study, $26 \%$ of patients had sought advice for ganglion treatment because of pain. ${ }^{(12)}$ Our study showed that $42.5 \%$ of patients with ganglions complained of pain. Wang et al reported a series of nine patients with ulnar nerve deep branch compression by ganglions. ${ }^{(13)}$ Volar wrist ganglion presenting as a trigger finger has also been described. ${ }^{(14)}$

In a study of 236 patients, 58\% of ganglions resolved spontaneously without any treatment, and a recurrence rate of $39 \%$ was reported after surgical excision. ${ }^{(15)}$ In contrast, our recurrence rate after excision of ganglions was $4.5 \%$. However, in comparison to the earlier study, ours involved lower patient numbers, and it is possible that some patients with recurrence did not return for follow-up. Hence, it is possible that the true recurrence rate of ganglions may have been higher than what our data suggests. The method of excision may also lower recurrence rates: Head et al reported a $76 \%$ reduction in recurrence rate with open surgical resection compared to aspiration, ${ }^{(16)}$ while arthroscopic resection for volar wrist ganglions was described to have a recurrence rate ranging from $0 \%$ to $20 \%$. ${ }^{(17)}$

The second most common benign tumour excised in our study was GCTTS, which is also referred to as pigmented villonodular tenosynovitis. Our study suggests that distal to the MCPJs, GCTTSs are more commonly excised than ganglions. Reported recurrence rates of GCTTSs differ in the literature. During 31.5 months of follow-up, a $2.4 \%$ recurrence rate was noted in a study of 84 patients by Lautenbach et al. ${ }^{(18)}$ Darwish and Haddad reported a recurrence rate of $24 \%$ after excision of GCTTSs in a study of 52 patients; the GCTTSs most commonly arose from the thumb. ${ }^{(19)}$ In contrast, most of the GCTTSs in our study occurred on the index finger, with none arising from the thumb. No recurrence was found, although this may be due to our small sample size. In a retrospective 12-year study of 96 patients with GCTTSs, Lancigu et al found that recurrence after excision typically occurred within 36 months. ${ }^{(20)}$ The Ki-67 proliferation index and mitotic activity were increased in patients with recurrence compared to those without recurrence. ${ }^{(21)}$ As recurrence rates are high for common hand tumours, it is important to consider likely differential diagnoses, as they can help clinicians to better plan surgical treatment for patients.

The limitations of this study include its retrospective nature and the study design, which included only patients who underwent surgery. Another shortcoming was the small number of patients enrolled. To determine the true prevalence of hand tumours in the local population, a prospective study that includes all hand tumours seen in the clinic is required.

Overall, the present study showed that ganglion was the most common tumour excised from between the MCPJs and RCJ, while GCTTS was the most common tumour distal to the MCPJs. Data from this study should improve the differential diagnoses of hand tumours based on their anatomical distribution.

\section{REFERENCES}

1. Athanasian EA. Bones and Soft Tissue Tumors. In: Wolfe SW, Hotchkiss RN, Pederson WC, Kozin SH, Cohen M. Green's Operative Hand Surgery. 6th ed. Elsevier: Churchill Livingstone, 2011: 2141-95.

2. Garcia J, Bianchi S. Diagnostic imaging of tumors of the hand and wrist. Eur Radiol 2001; 11:1470-82.

3. Kransdorf MJ, Meis JM. From the archives of the AFIP. Extraskeletal osseous and cartilaginous tumors of the extremities. Radiographics 1993; 13:853-84.

4. Simon MJ, Pogoda P, Hövelborn F, et al. Incidence, histopathologic analysis and distribution of tumours of the hand. BMC Musculoskelet Disord 2014; 15:182.

5. Ohta $\mathrm{H}, \mathrm{Nakano} \mathrm{T}$, Kojima $\mathrm{N}$, et al. A case of malignant lymphoma of the hand. Ann Nucl Med 2000; 14:387-9.

6. Baumhoer D, Jundt G: Tumours of the hand: a review on histology of bone malignancies. J Hand Surg Eur Vol 2010; 35:354-61.

7. Athanasian EA, Wold LE, Amadio PC. Giant cell tumors of the bones of the hand. J Hand Surg Am 1997; 22:91-8.

8. Glowacki KA, Weiss AP. Giant cell tumors of tendon sheath. Hand Clin 1995; 11:245-53.

9. Campbell DA, Millner PA, Dreghorn CR. Primary bone tumours of the hand and wrist. J Hand Surg Br 1995; 20:5-7.

10. Besser E, Roessner A, Brug E, et al. Bone tumors of the hand. A review of 300 cases documented in the Westphalian Bone Tumor Register. Arch Orthop Trauma Surg 1987; 106:241-7

11. Barnes WE, Larsen RD, Posch JL. Review of ganglia of the hand and wrist with analysis of surgical treatment. Plast Reconstr Surg 1964; 34:570-8.

12. Westbrook AP, Stephen AB, Oni J, Davis TR. Ganglia: the patient's perception. J Hand Surg Br 2000; 25:566-7.

13. Wang B, Zhao Y, Lu A, Chen C. Ulnar nerve deep branch compression by a ganglion: a review of nine cases. Injury 2014; 45:1126-30.

14. Macdonald A, Wood R, Chapman P. Volar wrist ganglion presenting as trigger finger. J Hand Surg Eur Vol 2013; 38:327-8.

15. Dias JJ, Dhukaram V, Kumar P. The natural history of untreated dorsal wrist ganglia and patient reported outcome 6 years after intervention. J Hand Surg Eur Vol 2007; 32:502-8.

16. Head L, Gencarelli JR, Allen M, Boyd KU. Wrist ganglion treatment: systematic review and meta-analysis. J Hand Surg Am 2015; 40:546-53.e8.

17. Fernandes $\mathrm{CH}$, Miranda CD, Dos Santos JB, Faloppa F. A systemic review of complications and recurrence rate of arthroscopic resection of volar wrist ganglion. Hand Surg 2014; 19:475-80.

18. Lautenbach M, Kim S, Millrose M, Eisenschenk A. Nodular giant cell tumour of the tendon sheath of the hand: analysis of eighty-four cases: diagnostic decisions and outcome. Int Orthop 2013; 37:2211-5.

19. Darwish FM, Haddad WH. Giant cell tumour of tendon sheath: experience with 52 cases. Singapore Med J 2008; 49:879-82.

20. Lancigu R, Rabarin F, Jeudy J, et al. Giant cell tumors of the tendon sheaths in the hand: review of 96 patients with an average follow-up of 12 years. Orthop Traumatol Surg Res 2013; 99(4 Suppl):S251-4.

21. Bedir R, Balik MS, Sehitoglu I, Güçer H, Yurdakul C. Giant Cell Tumour of the Tendon Sheath: Analysis of 35 Cases and their Ki-67 Proliferation Indexes. J Clin Diagn Res 2014; 8:FC12-5. 